\title{
Equi-lasting doses of rocuronium, compared to mivacurium, result in improved neuromuscular blockade in patients undergoing gynecological laparoscopy
}

\author{
[Des doses de durée équivalente de rocuronium, comparé au mivacurium, améliorent la \\ curarisation chez des patientes qui subissent une laparoscopie gynécologique]
}

Ashraf A. Dahaba MD MSc, Ekkehard Schweitzer MD, Robert D. Fitzgerald MD, Sylvia Schwarz MD

Purpose: To compare equi-lasting doses of a short-acting (mivacurium) to an intermediate-acting (rocuronium) neuromuscular relaxant, with regard to intubating conditions, efficacy, number of maintenance doses, hemodynamic alterations, adverse events and costs, in patients undergoing laparoscopic gynecological surgery.

Methods: Sixty patients were randomly allocated to receive either $0.2 \mathrm{mg} \cdot \mathrm{kg}^{-1}\left(3 \times \mathrm{ED}_{95}\right)$ mivacurium or $0.5 \mathrm{mg} \cdot \mathrm{kg}^{-1}\left(1.7 \times \mathrm{ED}_{95}\right)$ rocuronium, under propofol/fentanyl anesthesia. TI, first twitch of the train-of-four (TOF) and TOF ratio (T4:TI) were used to evaluate neuromuscular block using the Relaxometer ${ }^{\circledR}$ mechanomyograph. The trachea was intubated when $\mathrm{TI}$ was maximally suppressed. Neuromuscular block was maintained at 25\% TI with equi-lasting doses of $0.075 \mathrm{mg} \cdot \mathrm{kg}^{-1}$ mivacurium or $0.15 \mathrm{mg} \cdot \mathrm{kg}^{-1}$ rocuronium.

Results: Mean $(\mathrm{min}) \pm \mathrm{SD}$ mivacurium onset time $(1.9 \pm 0.4)$ was longer than that of rocuronium ( $1.3 \pm 0.3)$. This did not yield a statistical difference in intubating conditions between the two groups. Interval 25-75\% TI recovery and time to 0.8 TOF recovery were prolonged following rocuronium ( I I.9 $\pm 3.9,52.6 \pm 15.5$ respectively) compared to mivacurium $(6.7 \pm 2.3,39.2 \pm 8.1$ respectively). More patients, 22/30, required mivacurium maintenance doses compared to $14 / 30$ patients in the rocuronium group. Arterial blood pressure declined and 13/30 patients manifested erythema following mivacurium administration. The acquisition costs of rocuronium (6.93 Euro/patient) were 23\% lower compared to mivacurium (8.96 Euro/patient).

Conclusion: Equi-lasting doses of rocuronium resulted in favourable intubating conditions more rapidly, improved hemodynamic stability, required less frequent administration of maintenance doses and were not associated with erythema, compared to mivacurium.
Objectif : Comparer des doses de durée équivalente d'un myorelaxant à action brève, le mivacurium à celles d'un myorelaxant à effet intermédiaire, le rocuronium, quant aux conditions de l'intubation, l'efficacité, le nombre de doses de maintien, les changements hémodynamiques, les incidents et le coût, chez des patientes qui subissent une laparoscopie gynécologique.

Méthode : Soixante patientes ont été réparties au hasard et ont reçu, soit $0,2 \mathrm{mg} \cdot \mathrm{kg}^{-1}\left(3 \times E D_{95}\right)$ de mivacurium, soit $0,5 \mathrm{mg} \cdot \mathrm{kg}^{-1}(1,7 \times$ $\left.E D_{95}\right)$ de rocuronium, sous une anesthésie au propofol et au fentanyl. $T I$, première stimulation d'un train-de-quatre (TDQ) et le ratio du TDQ (T4: TI) ont permis d'évaluer la curarisation avec un relaxomécanomyographe. L'intubation a été réalisée après la suppression maximale de TI. La curarisation a été maintenue à $25 \%$ de TI par des doses de durée équivalente de $0,075 \mathrm{mg} \cdot \mathrm{kg}^{-1}$ de mivacurium ou de $0,15 \mathrm{mg} \cdot \mathrm{kg}^{-1}$ de rocuronium.

Résultats : Le délai d'installation moyen (min) [ \pm l'écart type] du mivacurium $(1,9 \pm 0,4)$ a été plus long que celui du rocuronium $(1,3$ $\pm 0,3)$. Ce résultat ne fournit pas de différence statistique intergroupe. La récupération dans l'intervalle 25-75\% TI et le temps nécessaire à la récupération à 0,8 du TDQ se sont prolongés avec le rocuronium (11,9 9 3,9,52,6 $\pm 15,5$ respectivement) comparé au mivacurium (6,7 $\pm 2,3,39,2 \pm 8,1$ respectivement). Un plus grand nombre de patientes, 22/30, ont eu besoin de doses de maintien de mivacurium, comparativement à 14/30 patientes ayant reçu du rocuronium. La tension artérielle a baissé et 13/30 patientes ont manifesté de l'érythème à la suite de l'administration de mivacurium. Le coût d'achat du rocuronium (6,93 Euros/patiente) a été de $23 \%$ plus bas que celui du mivacurium (8,96 Euros/patiente).

Conclusion : Des doses de durée équivalente de rocuronium, comparé au mivacurium, ont permis une intubation plus précoce, amélioré

From the Department of Anaesthesia and Intensive Care, Lainz Hospital and the Ludwig Boltzmann Institute for Economics of Medicine in Anaesthesia and Intensive Care, Vienna, Austria.

Address correspondence to: Dr. Ashraf Dahaba, Department of Anaesthesiology and Intensive Care Medicine, Karl Franzens University, Auenbruggerplatz 29, A-8036, Graz, Austria, Europe. Phone: ++ 43316385 2829; Fax: ++ 43316385 3267;

E-mail: Ashraf.Dahaba@kfunigraz.ac.at

Accepted for publication August 10, 2001.

Revision accepted September 12, 2001. 
la stabilité hémodynamique, exigé des doses de maintien moins fréquentes et n'ont pas été associées à un érythème.

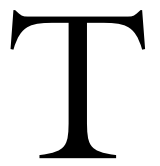

HE increasing importance of laparoscopic surgery has focussed the interest of anesthesiologists on the optimal choice of anesthetics and analgesics for such procedures. The often extremely variable duration of these operations specially confronts the anesthesiologist with the choice of the most appropriate neuromuscular blocking agent (NMBa). Several factors influence the decision of the anesthesiologist. These include tracheal intubation conditions, duration of neuromuscular block, need for maintenance doses, recovery characteristics, demand for reversal, safety, cardiovascular stability as well as costs associated with the use of a specific NMBa.

One of the questions discussed in this context is the preference of a short-acting $v s$ an intermediate-acting NMBa. While one promises more accurate timing of neuromuscular block, the other guarantees a more constant block and requires less frequent dosing. Two NMBa commonly used for this indication are mivacurium chloride and rocuronium bromide. Mivacurium is a nondepolarizing benzylisoquinolium diester with an intermediate onset and a short duration $\left(\mathrm{ED}_{95}\right.$ $\left.0.067 \mathrm{mg} \cdot \mathrm{kg}^{-1}\right),{ }^{1}$ while rocuronium is a nondepolarizing aminosteroid with a short onset and an intermediate duration $\left(\mathrm{ED}_{95} 0.305 \mathrm{mg} \cdot \mathrm{kg}^{-1}\right){ }^{2}$

The aim of the study was to compare two regimens of equi-lasting doses of mivacurium or rocuronium in patients undergoing scheduled laparoscopic gynecological surgical procedures of short to medium duration. We evaluated these regimens with regard to intubating conditions, efficacy, number of maintenance doses, recovery pattern, hemodynamic alterations, adverse events and costs.

\section{Methods}

Study design

A prospective controlled clinical randomized doubleblind consecutive study was conducted in conformity with the guidelines of "Good clinical research practice (GCRP) in pharmacodynamic studies of neuromuscular blocking agents", ${ }^{3}$ and the "Consolidated standards of reporting trials (CONSORT)-statement".

After approval of our local Ethics Committee, all patients who agreed to participate in the study gave written informed consent. We excluded potential participants if they had a history of neuromuscular disease, small joint arthritis, $20 \%$ deviation from ideal body weight or were on treatment with drugs thought to interfere with neuromuscular transmission. None of the female participants was pregnant or breast feeding. Sixty consecutive patients aged 18-59 yr, ASA Class I-II, undergoing scheduled elective laparoscopic gynecological surgical procedures expected to last 30 min to two hours were recruited in the study. Patients were randomly allocated to receive either mivacurium or rocuronium according to a computer generated randomization list (MS Excel 7.0 for Windows office 97). An assigned anesthesia nurse, the only one with access to the randomization code, prepared the NMBa initial and maintenance doses from $5-\mathrm{mL}\left(2 \mathrm{mg} \cdot \mathrm{mL}^{-1}\right)$ mivacurium or $5-\mathrm{mL}\left(10 \mathrm{mg} \cdot \mathrm{mL}^{-1}\right)$ rocuronium ampoules. The anesthesiologist and all other operating room personnel were blinded to the type of NMBa used. Recruitment was four to five patients/week in the period from April $3^{\text {rd }} 2001$ until June $30^{\text {th }} 2001$.

\section{Anesthesia protocol and neuromuscular monitoring} Midazolam $7.5 \mathrm{mg}$ po was administered for premedication one hour preoperatively. Anesthesia was induced with 3-4 $\mu \mathrm{g} \cdot \mathrm{kg}^{-1}$ fentanyl and $2-4 \mathrm{mg} \cdot \mathrm{kg}^{-1}$ propofol until the eyelash reflex was obtunded. After intubation (see below), the lungs were ventilated mechanically with $40 \%$ oxygen in air. Anesthesia was maintained with 6-9 $\mathrm{mg} \cdot \mathrm{kg}^{-1} \cdot \mathrm{hr}^{-1}$ propofol infusion, and 50-100 $\mu \mathrm{g}$ fentanyl supplements. Ventilation was adjusted to maintain an end-tidal $\mathrm{CO}_{2}$ in the range of $35-40 \mathrm{mmHg}$ and peripheral oxygen saturation above $95 \%$. Hemodynamic variables were recorded noninvasively every three minutes. Adverse events, including erythema, postoperative nausea and vomiting (PONV) were recorded by the anesthesiologist, anesthesia nurses, postanesthesia care unit (PACU) nurses or ward nurses blinded to the type of NMBa used.

Following induction, the right arm was positioned comfortably on an arm board and was restrained from movement by straps. The area above the ulnar nerve at the wrist, where the electrodes were to be placed, was cleaned to ensure adequate contact. The neuromuscular block at the adductor pollicis muscle was evaluated using the Relaxometer ${ }^{\circledR}$ mechanomyograph (Groningen University, Holland). ${ }^{5}$ The force transducer was attached to the thumb. The ulnar nerve was stimulated supramaximally at the wrist (pulse width 200 $\mu s$, square wave) via surface electrodes with train-offour (TOF) stimuli ( $2 \mathrm{~Hz}$ for two seconds) at 12 -sec intervals until a stable control response was achieved (variation of less than $\pm 2 \%$ for the last three minutes). During stabilization, patients were ventilated with oxygen via a face mask. The preload on the thumb was 
maintained between 200-400 g throughout the whole procedure. Tl (first twitch of the TOF) expressed as percentage of control response and the TOF ratio (T4:Tl) were used for the evaluation of neuromuscular block. Artefact readings were filtered by discarding all measurements that changed by more than $15 \%$ compared to the previous readings. Palmar skin temperature of the thenar area was monitored by the temperature probe of the mechanomyograph. Patients were warmed (Bair Hugger ${ }^{\mathrm{TM}}$ Augustine Medical) to keep the temperature of the hand always above $32^{\circ} \mathrm{C}$.

After Tl baseline stabilization, initial doses of equilasting duration 25\% (time from beginning of $\mathrm{NMBa}$ administration until $25 \% \mathrm{Tl}$ recovery) under balanced anesthesia, of either $0.2 \mathrm{mg} \cdot \mathrm{kg}^{-1}\left(3 \times \mathrm{ED}_{95}\right)$ mivacurium expected to last for $21.3 \mathrm{~min},{ }^{6}$ or $0.5 \mathrm{mg} \cdot \mathrm{kg}^{-1}$ ( 1.7 $\mathrm{x} \mathrm{ED}_{95}$ ) rocuronium expected to last for $21.2 \mathrm{~min},{ }^{7}$ were administered over a period of $30 \mathrm{sec}$. The trachea was intubated when $\mathrm{Tl}$ was suppressed maximally. Intubating conditions were graded as; excellent (no resistance to laryngoscopy, no movement of vocal cords, limbs or coughing), good (slight resistance to laryngoscopy, movement of vocal cords, limbs or diaphragm), poor (active resistance of the patient to laryngoscopy, closing of vocal cords, vigorous movement of the limbs or coughing). ${ }^{8}$ Neuromuscular block was maintained with equi-lasting doses of 0.075 $\mathrm{mg} \cdot \mathrm{kg}^{-1}$ mivacurium, ${ }^{1}$ or $0.15 \mathrm{mg} \cdot \mathrm{kg}^{-1}$ rocuronium, ${ }^{9}$ each time $\mathrm{Tl}$ recovered to $25 \%$.

Twenty minutes before the anticipated end of the operation, no further NMBa was administered, and the patients were allowed to recover spontaneously from the neuromuscular block. Recovery from neuromuscular block was not accelerated by cholinesterase inhibiting drugs, based upon reports that reversal of $0.2 \mathrm{mg} \cdot \mathrm{kg}^{-1}$ mivacurium neuromuscular blockade in laparoscopic gynecological surgery was associated with a significantly higher incidence of PONV. ${ }^{10,11}$ At the end of surgery, after 0.8 TOF ratio recovery, anesthesia and neuromuscular recording were terminated. Patients were ventilated with $100 \%$ oxygen and were extubated after they maintained adequate respiration ( 8 breaths min $^{-1}$ and $\mathrm{P}_{\mathrm{ET}} \mathrm{CO}_{2}<45 \mathrm{mmHg}$ ) and were responsive to verbal commands. After patients showed full control of their airway, maintained a head lift for ten seconds, and tightly squeezed the anesthesiologist's hand, they were discharged to the PACU.

\section{Calculations (min)}

- Onset time: time from beginning of $\mathrm{NMBa}$ administration until Tl was suppressed maximally.

- Duration 10\%: time from beginning of $\mathrm{NMBa}$ administration until $10 \% \mathrm{Tl}$ recovery.
- Complete recovery time: time from beginning of NMBa administration until 0.8 TOF ratio recovery in patients who required no maintenance doses.

- Interval $25-75 \%$ : time of $\mathrm{Tl}$ recovery from $25 \%$ to $75 \%$.

- Interval 10-90\%: time of $\mathrm{Tl}$ recovery from $10 \%$ to $90 \%$ in patients who required no maintenance doses.

- Interval $25 \%$ to TOF 0.8: time from $25 \% \mathrm{Tl}$ until 0.8 TOF ratio recovery.

- Time to beginning of surgery: time from beginning of anesthesia induction until skin incision.

- Duration of surgery: time from skin incision until end of surgery.

- Recovery time: time from end of surgery until extubation.

- Time to discharge: time from extubation until dis charge to PACU.

Costs

The drug acquisition costs were calculated using the commercial price and the number of mivacurium or rocuronium ampoules used for each patient and are presented in Euro $(\epsilon)$. The indirect cost was estimated, based upon our hospital's costs of running an operating room for laparoscopic gynecological procedure/hour.

\section{Statistical analysis}

We considered the interval 25-75\%, following 0.2 $\mathrm{mg} \cdot \mathrm{kg}^{-1}$ mivacurium or $0.5 \mathrm{mg} \cdot \mathrm{kg}^{-1}$ rocuronium, as the primary clinical variable upon which a priori power analysis for $\mathrm{t}$ test was performed. Based upon previously reported data, ${ }^{6,7}$ an assumed interval $25-75 \%$ of nine minutes with a SD of 3.3 , revealed that a group size of 30 would be required to detect a three-minute difference between the two groups with $>0.9$ power.

As our data displayed normal distribution, paired $t$ test was used for the parametric data and MannWhitney $U$ test was used for nonparametric data analysis. Repeated measures analysis of variance (ANOVA) was used for the analysis of the hemodynamic variables (group-time interaction). Data were expressed as means \pm SD. $P<0.05$ was considered statistically significant.

Results

The two groups were comparable with respect to age, height, weight, as well as fentanyl and propofol requirements. There was no difference in the time to beginning of surgery, duration of surgery or time to discharge, between the two groups. However the 
TABLE I Demographic data, anesthetic requirements and duration of anesthesia and surgery

\begin{tabular}{|c|c|c|c|}
\hline & $\begin{array}{l}\text { Mivacurium } \\
(n=30)\end{array}$ & $\begin{array}{l}\text { Rocuronium } \\
(n=30)\end{array}$ & P value \\
\hline$\overline{\text { Age }(y r)}$ & $36.5 \pm 7$ & $36.4 \pm 9.8$ & 0.952 \\
\hline Height $(\mathrm{cm})$ & $167 \pm 7$ & $165 \pm 6$ & 0.26 \\
\hline Weight (kg) & $62 \pm 11$ & $62 \pm 10$ & 0.99 \\
\hline Fentanyl bolus ( $\mu \mathrm{g})$ & $358.3 \pm 132$ & $363.3 \pm 143.8$ & 0.889 \\
\hline Propofol bolus $\left(\mathrm{mg} \cdot \mathrm{kg}^{-1}\right)$ & $2.5 \pm 0.5$ & $2.4 \pm 0.5$ & 0.403 \\
\hline $\begin{array}{l}\text { Propofol infusion } \\
\left(\mathrm{mg} \cdot \mathrm{kg}^{-1} \cdot \mathrm{hr}^{-1}\right)\end{array}$ & $8.3 \pm 1.5$ & $5.4 \pm 0.8$ & 0.364 \\
\hline $\begin{array}{l}\text { Time to beginning of } \\
\text { surgery ( } \mathrm{min})\end{array}$ & $24.5 \pm 6.5$ & $23 \pm 5.8$ & 0.372 \\
\hline Duration of surgery $(\mathrm{min})$ & $57.9 \pm 37.3$ & $50.9 \pm 33.1$ & 0.443 \\
\hline Recovery time (min) & $8.1 \pm 4.9$ & $14.1 \pm 10.1$ & 0.005 \\
\hline Time to discharge (min) & $7.7 \pm 3.7$ & $8.8 \pm 4$ & 0.333 \\
\hline
\end{tabular}

All values are presented as mean $\pm \mathrm{SD}$

TABLE II Pharmacodynamic variables following the initial dose of NMBa

\begin{tabular}{llll}
\hline & Mivacurium & Rocuronium & P value \\
\hline Duration 10\% & $17.5 \pm 4.2$ & $21.3 \pm 5.3$ & 0.003 \\
Duration 25\% & $19.9 \pm 4.4$ & $25.8 \pm 6.5$ & 0.0001 \\
Interval 25-75\% & $6.7 \pm 2.3$ & $11.9 \pm 3.9$ & 0.00001 \\
Interval 10-90\% & $12.2 \pm 3.9^{*}$ & $21 \pm 7.9 \dagger$ & 0.000001 \\
Interval 25\% to TOF 0.8 & $14.9 \pm 4.8$ & $30.4 \pm 12.6$ & 0.000001 \\
Complete recovery time & $39.2 \pm 8.1^{*}$ & $52.6 \pm 15.5 \dagger$ & 0.033 \\
\hline
\end{tabular}

Mean $(\min ) \pm \mathrm{SD}, n=30,{ }^{*} n=8, \dagger n=16$. Duration $10 \%=$ time to $10 \% \mathrm{Tl}$ recovery; duration $25 \%=$ time to $25 \% \mathrm{Tl}$ recovery; interval $25-75 \%=$ time of $\mathrm{Tl}$ recovery from $25 \%$ to $75 \%$; interval $10-90 \%=$ time of $\mathrm{Tl}$ recovery from $10 \%$ to $90 \%$; interval $25 \%$ to train-of-four (TOF) $0.8=$ time from $25 \% \mathrm{Tl}$ until $0.8 \mathrm{TOF}$ ratio recovery; complete recovery time=time to $0.8 \mathrm{TOF}$ ratio recovery.

TABLE III Pharmacodynamic variables following the last maintenance dose

\begin{tabular}{llll}
\hline $\begin{array}{l}\text { No of } \\
\text { doses }\end{array}$ & Variable & $\begin{array}{l}\text { Mivacurium } \\
(n=22)\end{array}$ & $\begin{array}{l}\text { Rocuronium } \\
(n=14)\end{array}$ \\
\hline 1 & Interval 25-75\% & $6.8 \pm 2.3$ & $12.5 \pm 3.9$ \\
& Interval 25\% to TOF 0.8 & $16.8 \pm 4.7$ & $29.5 \pm 12.1$ \\
2 & Interval 25-75\% & $6.1 \pm 2.1$ & $12.7 \pm 3.9$ \\
& Interval 25\% to TOF 0.8 & $12.7 \pm 4.8$ & $35.7 \pm 11.9$ \\
3 & Interval 25-75\% & $5.6 \pm 2.5$ & $16 \pm 3.7$ \\
& Interval 25\% to TOF 0.8 & $13.1 \pm 4.2$ & $54.7 \pm 12.5$ \\
4 & Interval 25-75\% & $4.3 \pm 2.3$ & $9 \pm 4$ \\
& Interval 25\% to TOF 0.8 & $10.3 \pm 5.1$ & $25.9 \pm 12$ \\
\hline
\end{tabular}

Mean $(\mathrm{min}) \pm \mathrm{SD}$. Interval $25-75 \%=$ time of $\mathrm{Tl}$ recovery from $25 \%$ to $75 \%$; interval $25 \%$ to train-of-four (TOF) $0.8=$ time from $25 \% \mathrm{Tl}$ until $0.8 \mathrm{TOF}$ ratio recovery.

recovery time was prolonged in the rocuronium group compared to the mivacurium group (Table I).

A mivacurium onset time of $1.9 \pm 0.4$ min yielded excellent intubating conditions in $16 / 30$ patients, good in $11 / 30$ and poor in $3 / 30$ patients, while a rocuronium onset time of $1.3 \pm 0.3$ min yielded excellent intubating conditions in $14 / 30$ patients, good in $13 / 30$ patients and poor in $3 / 30$ patients. Although the mivacurium onset time was longer than that of rocuronium, there was no statistical difference in the intubating conditions between the two groups. All the other pharmacodynamic variables were prolonged in the rocuronium group compared to the mivacurium group (Table II).

Twenty two/30 patients required maintenance mivacurium doses, which was more than the $14 / 30$ patients in the rocuronium group $(P<0.001)$. Time between maintenance doses was shorter in the mivacurium group $(12.3 \pm 3.3 \mathrm{~min})$ compared to the rocuronium group $(16.8 \pm 6.8 \mathrm{~min})$ and the total number of mivacurium maintenance doses (59) was more than that in the rocuronium group (24). Interval $25-75 \%$ and interval $25 \%$ to TOF 0.8 follow ing the last maintenance dose administration were longer $(P<0.00001)$ in the rocuronium group compared to the mivacurium group (Table III).

There was no change in the heart rate (HR) following NMBa administration. Systolic arterial pressure (SAP) and diastolic arterial pressure (DAP) declined following the initial dose of mivacurium, while there was no change following administration of rocuronium. In both groups, there was a rise in SAP, DAP and HR following intubation (Figure). There was no difference in the hemodynamic variables during anesthesia between the two groups.

Thirteen/30 patients manifested erythema following mivacurium administration, while this was not manifested in any of the patients receiving rocuronium. None of the patients in our study experienced PONV or other adverse events that could be related to the NMBa.

Patients in the mivacurium group required 92 ampoules (range 1-4/patient), while patients in the rocuronium group required 39 ampoules (range $1-2 /$ patient). The drug acquisition cost in the rocuronium group $(6.93 \mathrm{\epsilon} /$ patient $)$ was less than in the mivacurium group $(8.96 \epsilon /$ patient $)$. In our hospital the costs of running the operating room for laparoscopic gynecological procedures is approximately 450 $\epsilon /$ hour. Thus, if the recovery from neuromuscular block is not accelerated by the administration of anticholinesterase drugs, the six-minute prolongation in the recovery time in the rocuronium group would represent an additional, indirect cost of $45 \epsilon$ /patient.

\section{Discussion}

Progress in pharmaceutical research has provided anesthesiologists with a multitude of drugs allowing an 


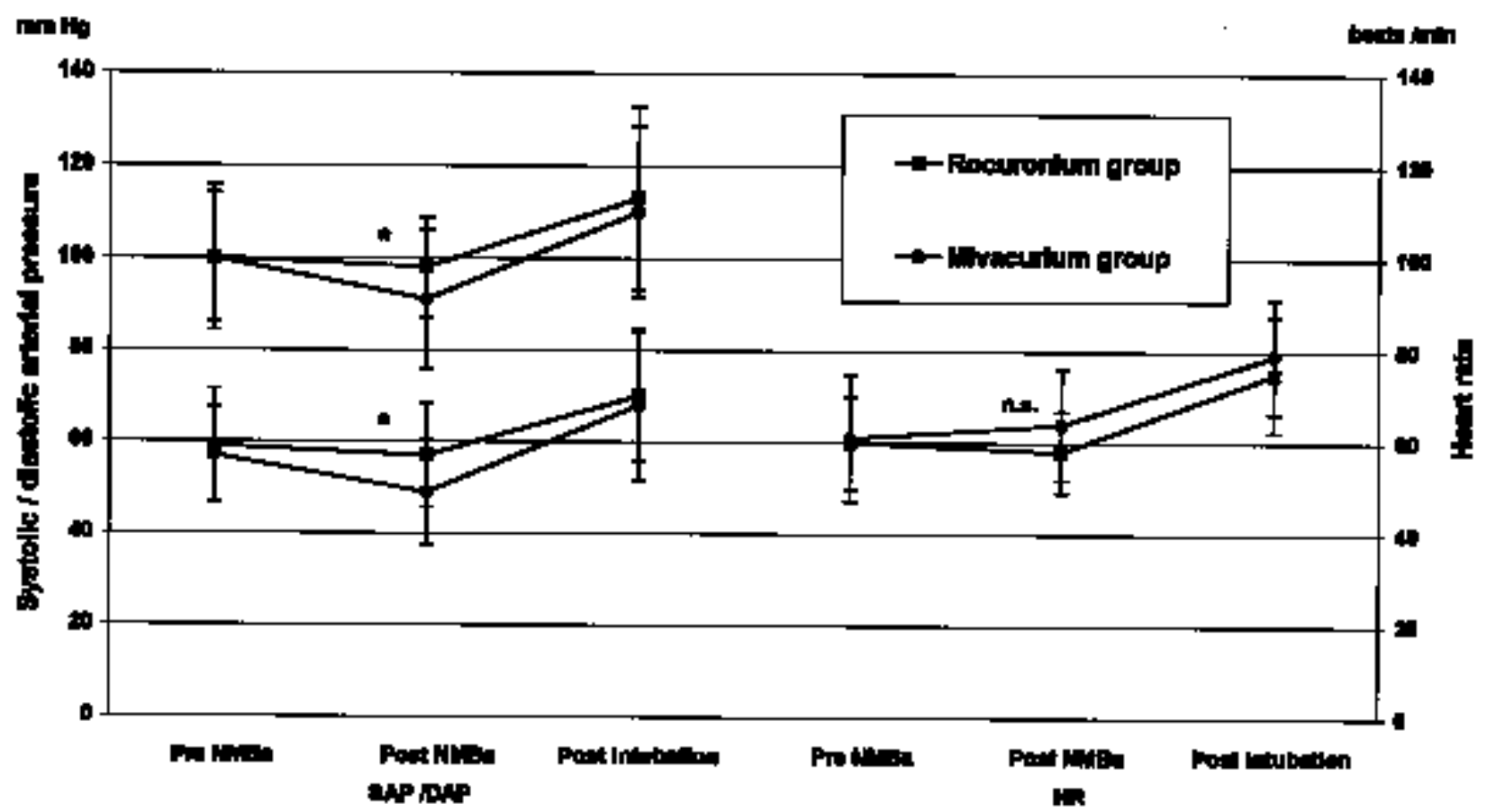

FIGURE: Systolic/diastolic arterial pressure and heart rate. Mean $\pm \mathrm{SD}$, repeated measures ANOVA, ${ }^{*}$ P $<0.05$, n.s.: no significant difference, neuromuscular blocking agents $(\mathrm{NMBa})$, systolic/diastolic arterial pressure (SAP/DAP), heart rate $(\mathrm{HR})$

almost tailored use for different indications. However, clinical benefits are always accompanied by increasing costs and sometimes increased monitoring requirements. This emphasizes the need for clear indications for the use of different regimens. Laparoscopic surgery is specially challenging to the anesthesiologist who is confronted with an often undefined duration of surgery.

\section{Intubating conditions}

Our results demonstrate that waiting for maximal suppression of twitch response, rather than attempting tracheal intubation at a predetermined time, yields similar intubating conditions though at different onset times following mivacurium or rocuronium administration.

The intubating conditions following rocuronium administration were in accordance with those previously reported using a dose of $0.5 \mathrm{mg} \cdot \mathrm{kg}^{-1}$, the same as that used in the present study. ${ }^{7}$ Three studies used the same dose of $0.2 \mathrm{mg} \cdot \mathrm{kg}^{-1}$ mivacurium as we did while attempting tracheal intubation at different time points from NMBa administration. There was no apparent difference in intubating conditions when intubation was attempted at $1.5 \mathrm{~min},{ }^{12}$ when it was delayed to two minutes, ${ }^{13}$ or with a further delay to $2.5 \mathrm{~min}^{14}$

Our findings suggests that waiting for maximal twitch suppression might be a better indicator to achieve optimal intubating conditions. ${ }^{8}$

Pharmacodynamic variables and maintenance doses Duration $25 \%$ and all other pharmacodynamic variables were prolonged in the rocuronium group compared to the mivacurium group. The different maintenance dose profile between the two groups resulted in a longer recovery time (six minutes) in the rocuronium group compared to the mivacurium group.

Our results are in accordance with the literature following the administration of $0.2 \mathrm{mg} \cdot \mathrm{kg}^{-1}$ mivacurium, in which the duration $25 \%$ under balanced anesthesia, was $21.3 \mathrm{~min}(n=7)^{6}$ and $19.7 \mathrm{~min}(n=10) .^{15}$ However the duration $25 \%$ following $0.5 \mathrm{mg} \cdot \mathrm{kg}^{-1}$ rocuronium, in our study, was longer than the reported values under balanced anesthesia of $21.2 \mathrm{~min}$ $(n=11)^{7}$ and $22 \mathrm{~min}(n=7) \cdot{ }^{16} \mathrm{~A}$ possible reason for this divergence could be a larger number of patients than those used in the above mentioned descriptive studies 
was required in our comparative study.

\section{Hemodynamic variables}

Two studies demonstrated a decline in mean arterial pressure following rapid administration of $0.2 \mathrm{mg} \cdot \mathrm{kg}^{-1}$ mivacurium, either over two to three seconds, ${ }^{17}$ or 10-15 sec. ${ }^{18}$ However, when mivacurium was administered in more than $30 \mathrm{sec}$ the authors reported no significant decline from baseline. ${ }^{17,18}$ This is in contrast to our results whereby mivacurium administration in more than $30 \mathrm{sec}$ was still associated with a significant decline in SAP and DAP. This decline lasted only until the tracheal intubation and thus required no intervention.

The hemodynamic stability following the administration of rocuronium in our patients is in accordance with two studies in which increasing doses of $0.6,{ }^{19}$ and 0.6 , $0.9,1.2 \mathrm{mg} \cdot \mathrm{kg}^{-1}$ rocuronium ${ }^{2}{ }^{0}$ were not associated with significant changes in mean arterial pressure or HR.

\section{Adverse events}

No erythema occurred in patients receiving rocuronium. The incidence of erythema experienced by patients receiving mivacurium was relatively high. It was approximately double that reported in a previous study using $0.2 \mathrm{mg} \cdot \mathrm{kg}^{-1}$ mivacurium ${ }^{12}$

Costs

The costs of running an operating room vary between different hospitals. The drug acquisition costs in the rocuronium patients were $23 \%$ lower than in the mivacurium patients. However, in our hospital, this could be offset by the higher indirect cost of their delayed recovery if residual neuromuscular block is not reversed.

Worth mentioning is the fact that, to allow our patients to recover spontaneously from neuromuscular block, they were monitored closely to ensure full recovery before extubation. However, using sensitive neuromuscular monitoring or waiting for the patients to recover spontaneously might not always be feasible in the clinical setting, and would thus necessitate reversal of neuromuscular blockade.

In conclusion, for laparoscopic gynecological surgery, equi-lasting doses of the intermediate acting $\mathrm{NMBa}$ rocuronium resulted in favourable intubating conditions more rapidly, improved hemodynamic stability, required less frequent administration of maintenance doses and were not associated with erythema, compared to the short-acting NMBa mivacurium. Finally, the acquisition costs of rocuronium were $23 \%$ lower but, in the absence of neuromuscular block reversal, recovery time was prolonged compared to mivacurium, representing an additional indirect cost.
References

1 Diefenbach C, Mellinghoff $H$, Lynch J, Buzello W. Mivacurium: dose-response relationship and administration by repeated injection or infusion. Anesth Analg 1992; 74: 420-3.

2 Foldes FF, Nagashima H, Nguyen HD, Schiller WS, Mason MM, Obta $\Upsilon$. The neuromuscular effects of ORG 9426 in patients receiving balanced anesthesia. Anesthesiology 1991; 75: 191-6.

3 Viby-Mogensen J, Engbaek J, Eriksson I, et al. Good clinical research practice (GCRP) in pharmacodynamic studies of neuromuscular blocking agents. Acta Anaesthesiol Scand 1996; 40: 59-74.

4 Moher D, Schulz KF, Altman DG for the CONSORT Group. The CONSORT statement: revised recommendations for improving the quality of reports of parallelgroup randomised trials. Lancet 2001; 357: 1191-4.

5 Rowaan CJ, Vandenbrom RHG, Wierda JMKH. The relaxometer: a complete and comprehensive computercontrolled neuromuscular transmission measurement system developed for clinical research on muscle relaxants. J Clin Monit 1993; 9: 38-44.

6 Caldwell JE, Heier T, Kitts JB, Lynam DP, Fabey MR, Miller RD. Comparison of the neuromuscular block induced by mivacurium, suxamethonium or atracurium during nitrous oxide-fentanyl anaesthesia. Br J Anaesth 1989; 63: 393-9.

7 Wierda JMKH, De Wit APM, Kuizenga K, Agoston S. Clinical observations on the neuromuscular blocking action of ORG 9426, a new steroidal non-depolarizing agent. Br J Anaesth. 1990; 64: 521-3.

8 Agoston $S$. Onset time and evaluation of intubating conditions: rocuronium in perspective. Eur J Anaesthesiol 1995; 12(Suppl. 11): 31-7.

9 Lambalk LM, De Wit APM, Wierda JMKH, Hennis PJ, Agoston S. Dose-response relationship and time course of action of Org 9426. A new muscle relaxant of intermediate duration evaluated under various anaesthetic techniques. Anaesthesia 1991; 46: 907-11.

10 Ding $\Upsilon$, Fredman B, White PF. Use of mivacurium during laparoscopic surgery: effect of reversal drugs on postoperative recovery. Anesth Analg 1994; 78: 450-4.

11 Lovstad RZ, Thagaard KS, Berner NS, Raeder JC Neostigmine $50 \mu \mathrm{g} \mathrm{kg}^{-1}$ with glycopyrrolate increases postoperative nausea in women after laparoscopic gynaecological surgery. Acta Anaesthesiol Scand 2001; 45: 495-500.

12 Tang J, Joshi GP, White PF. Comparison of rocuronium and mivacurium to succinylcholine during outpatient laparoscopic surgery. Anesth Analg 1996; 82: 994-8.

13 Goldhill DR, Whitehead JP, Emmott RS, Griffith AP, Bracey BJ, Flynn PJ. Neuromuscular and clinical effects of mivacurium chloride in healthy adult patients during 
nitrous oxide-enflurane anaesthesia. Br J Anaesth 1991; 67: 289-95.

14 Maddineni VR, Mirakhur RK, McCoy EP, Fee JPH, Clarke RSJ. Neuromuscular effects and intubating conditions following mivacurium: a comparison with suxamethonium. Anaesthesia 1993; 48: 940-5.

15 Savarese JJ, Ali HH, Basta SJ, et al. The clinical neuromuscular pharmacology of mivacurium chloride (BW B1090U). Anesthesiology 1988; 68: 723-32.

16 Meistelman C, Plaud B, Donati F. Rocuronium (ORG 9426) neuromuscular blockade at the adductor muscles of the larynx and adductor pollicis in humans. Can J Anaesth 1992; 39: 665-9.

17 Choi WW, Mehta MP, Murray DJ, et al. Neuromuscular and cardiovascular effects of mivacurium chloride in surgical patients receiving nitrous oxide-narcotic or nitrous oxide-isoflurane anaesthesia. Can J Anaesth 1989; 36: 641-50.

18 Savarese JJ, Ali HH, Basta SJ, et al. The cardiovascular effects of mivacurium chloride (BW B1090U) in patients receiving nitrous oxide- opiate-barbiturate anesthesia. Anesthesiology 1989; 70: 386-94.

19 McCoy EP, Maddineni VR, Elliott P, Mirakhur RK, Carson IW, Cooper RA Haemodynamic effects of rocuronium during fentanyl anaesthesia: comparison with vecuronium. Can J Anaesth 1993; 40: 703-8.

20 Levy JH, Davis GK, Duggan J, Szlam F. Determination of the haemodynamics and histamine release of rocuronium (Org 9426) when administered in increased doses under $\mathrm{N}_{2} \mathrm{O} / \mathrm{O}_{2}$-sufentanil anesthesia. Anesth Analg 1994; 78: 318-21. 